\title{
MUDANÇA CONCEITUAL E COMPORTAMENTAL NAS RELAÇÕES ENTRE SOCIEDADE, DESENVOLVIMENTO E SUSTENTABILIDADE
}

\author{
Alcemar Rodrigues Martello, Marta Tocchetto \\ 1armartello@hotmail.com, ${ }^{2}$ marta@tocchetto.com
}

\section{RESUMO}

É preciso conhecer os mecanismos de auto-regulação, as relações de integração e os níveis da autonomia da natureza e das sociedades humanas, para que possamos prevenir as possíveis perturbações do equilíbrio natural. Este trabalho teve como objetivo fazer uma breve exploração de alguns elementos relacionados a conceitos e fundamentos das perturbações existentes nas relações socioambientais das populações humanas demonstrando a mudança conceitual e comportamental nas relações entre sociedade, desenvolvimento e sustentabilidade. Este estudo trata-se de uma revisão desenvolvida exclusivamente a partir de fontes bibliográficas, com as seguintes abordagens: 1 ) as cidades e a capacidade adaptativa humana, na qual é enfatizado o organismo humano como um indicador de qualquer mudança que aconteça ao seu redor, tanto no setor da natureza, como no setor social; 2) a relação cultura e natureza, onde a cultura influencia o modo de conceber conceitos e prioridades; 3 ) a problemática ambiental, no qual é enfocado o problema ecológico humano tendo em vista que, todas as atividades que denominamos desenvolvimento implicam em interferência nos ecossistemas naturais; 4) os modos de produção e consumo, no qual se apresentam alternativas para minimizar os impactos ambientais a partir de novos padrões de consumo; 5) a ecologia industrial, na qual se relacionam os sistemas naturais com os industriais e; 6) a gestão ambiental nas empresas como uma ferramenta que permite reavaliar o processo produtivo. Verificou-se que alguns aspectos, tais como, a globalização da economia, a introdução de bens de consumo e tecnologias em países cuja economia era fechada, adequações às políticas e acordos internacionais tiveram maior inferência para a mudança dos modelos de desenvolvimento, na alteração das próprias sociedades e das concepções de sustentabilidade.

Palavras-chave: evolução social; ética; valores ambientais.

\section{ABSTRACT}

It's necessary to know the mechanisms of self-regulation, relationships and integration levels of autonomy of nature and human societies, so that you can prevent possible disruption of nature equilibrium. The aim of this work, a brief exploration of some elements of the concepts and fundamentals of social and environmental disruption in relations of human populations demonstrating the conceptual and behavioral change in the relations between society, development and sustainability. This study deals with a literature review developed exclusively from literature sources, with the following approaches: 1) cities and human adaptive capacity, emphasizing the human organism as an indicator of any change that happens around him, both in the nature, as in the social sector; 2 ) the relationship between culture and nature, in which culture influences the way of conceiving ideas and priorities; 3 ) the environmental problems, where the 
ecological problem is that all human activities which we call development tend to involve interference in natural ecosystems; 4) the methods of production and consumption, minimizing environmental impacts through new patterns of consumption; 5) on industrial ecology, natural relating to the industrial systems and; 6) the environmental management in companies, in search of a reassessment of the production process. It was found that some aspects such as economic globalization, the introduction of consumer goods and technologies in countries whose economy was closed, adjustment policies and international agreements had higher inference to change the models of development, changing own societies and the concepts of sustainability.

Keywords: social evolution, ethic, environmental values.

\section{INTRODUÇÃO}

Natureza e sociedade, natural e cultural, são conceitos geralmente usados como antagônicos e opostos, em vez de unificados. Ao formar a cultura, a humanidade desenvolveu um pensamento de independência e dominação da natureza, com a crescente preocupação de um benefício imediato. Essas questões são muito atuais dentro da dinâmica das modificações que o homem provocou no meio ambiente, alterando com isso, também as relações homem-natureza e homem-homem. A natureza existia muito antes do surgimento da humanidade. O homem é produto da natureza, assim, essas relações não podem ser rompidas. A questão fundamental está na compreensão sobre a relação que existe entre todas as coisas e a transitoriedade de sua existência. Os sistemas biológicos são autônomos. Os sistemas sociais, devido aos longos anos e de gerações, e processos de aperfeiçoamento buscam também uma capacidade de autonomia.

O processo da evolução do planeta e da vida existente nele condicionou a formação de relações mútuas entre os elementos da natureza. Essas relações e, provenientes destas, as dependências são diversas e diferentes em cada uma das etapas da evolução, produzindo, em efeito, formas de organização cada vez mais novas. Essas dependências possuem o caráter de auto-regulação, o que determina a sua autonomia. Tendo em vista que os elementos da natureza sofrem modificações no tempo e estão sendo diversificados no espaço, modifica-se também a totalidade do conjunto. Em realidade, o sistema de relações do conjunto não é algo estável (homeostasia), mas é o processo que sustenta o equilíbrio.

As conseqüências das perturbações em determinadas relações se transferem, normalmente, para os outros níveis de integração e autonomia, ameaçando assim a sua existência. $O$ desaparecimento das espécies vegetais e animais, como também das civilizações humanas, são fortes argumentos para uma nova relação de autonomia. As ameaças para a saúde e a existência provêm, nas comunidades contemporâneas, de abuso das relações naturais (homeostase) dentro dos ecossistemas. Provêm também dos sistemas não exatos de direcionamento sócio-econômico. Isso se refere, em especial, às experiências relativas ao domínio dos sistemas da natureza, que levam frequentemente as perturbações dos mecanismos da autoregulação.

A história da humanidade sempre foi dinâmica e marcada por profundas transformações, no que concerne às percepções e aos valores individuais e sociais. Certamente, o século XXI também assistirá a grandes mudanças em percepções e valores fundamentais que fazem a história e que movem os seres humanos (CAMARGO, 2003). É preciso conhecer os mecanismos de autoregulação, as relações de integração e os níveis da autonomia da natureza e das sociedades 
humanas, para que se possa prevenir as possíveis perturbações do equilíbrio e proteger, desse modo, a humanidade e a natureza.

Este estudo trata-se de uma revisão sobre o tema desenvolvido exclusivamente a partir de fontes bibliográficas com o objetivo de realizar uma breve exploração de alguns elementos relacionados aos conceitos e aos fundamentos das perturbações existentes nas relações socioambientais das populações humanas demonstrando a mudança conceitual e comportamental nas relações entre sociedade, desenvolvimento e sustentabilidade.

\section{DESENVOLVIMENTO}

\section{As cidades e a capacidade adaptativa humana}

O produto biológico da adaptação dos primeiros hominídeos era o desenvolvimento do cérebro e das funções intelectuais superiores. Com o passar do tempo, essas funções de controle comportamental, tornaram-se o elemento mais importante de adaptação às novas condições do que à adequação das próprias estruturas biológicas. Essas funções formaram uma nova qualidade, chamada cultura. Essa função substitutiva e subseqüente dos comportamentos culturais é possível perceber, quando o homem, ocupando os novos territórios climáticos, dominava os novos ecossistemas. Isto acontecia, por exemplo, no caso de territórios montanhosos (frio e insuficiência de oxigênio), secos (falta de água e de alimento) ou nos polares (frio). As adaptações culturais, nesses casos, foram as primeiras modificações biológicas para os futuros ajustes.

Nas fases iniciais do surgimento da humanidade, o homem - elemento da natureza integrava os ecossistemas. Com a introdução da agricultura e da criação de animais - tanto por causa do crescimento da intensidade das relações (monoculturas), quanto por meio do aumento numérico dos grupos humanos - o homem alterou os ecossistemas naturais. Com o desenvolvimento da agricultura e da irrigação, o homem, lotado num terreno, começou a formar um novo tipo de relação: urbicenose (WOLÁNSKI, 1989). O ecossistema urbano é o produto técnico do homem (feito com elementos retirados e transformados do ambiente natural). $O$ elemento mais importante da urbicenose é, porém, a sociedade humana junto com a sua cultura. O ecossistema urbano é, ao mesmo tempo, a forma cultural da adaptação do gênero humano e do ambiente.

As cidades surgem para o seu conforto. Esse processo de adaptação cultural da humanidade levou ao grande desenvolvimento das técnicas de aclimatização, de comunicação e de informação. Juntamente com a adaptação biológica e o acostumar psíquico, após algum tempo, desaparece o sentimento de satisfação e é sentida a necessidade de outras mudanças. O homem forma, neste modo, novas condições (modificadas em relação às anteriores). Durante algum tempo, o homem aproveita a satisfação, após acostumar-se e acomodar-se, para iniciar outras modificações, formando assim, um ciclo da busca por satisfação por meio de mudanças. Esses círculos, em espiral, convertem-se para um fim, ao qual chamamos progresso.

Com relação às cidades, o uso da noção de sustentabilidade urbana torna-se ainda mais complexo, pois os espaços urbanos são incapazes de satisfazer todas as necessidades humanas, sendo dependentes de outras espacialidades, próximas ou distantes; são grandes consumidores de energia; produzem enorme quantidade de resíduos, que não podem ser inteiramente eliminados ou reaproveitados; provocam profundas mudanças na ocupação da terra e no uso do 
solo, decorrentes da transformação de áreas naturais ou rurais em urbanas, gerando diversos impactos ambientais e socioeconômicos (ODUM, 1988).

A visão puramente biológica dos problemas do meio ambiente exclui o homem, por não considerá-lo como possuidor de características peculiares que o distingam dos demais seres vivos. É necessário considerar a sua dimensão cultural, ou seja, o homem como parte integrante do sistema ambiental, devendo, portanto participar, de forma racional, de seu equilíbrio e de sua estabilidade. Esse progresso provém de capacidades inerentes da psíquica humana, sendo produto das estruturas complexas do seu cérebro. Pode-se considerar, por isso, como natural, à tendência para o conforto, ao aumento de produção e de consumo, mais do que para as necessidades puramente biológicas, que servem para contentamento das necessidades emocionais e intelectuais. A medida de progresso de uma civilização é, num certo modo, o aumento das aspirações tipicamente humanas.

Como centro de trocas, de comércio, de recepção, transformação e armazenamento, isto é, um local de processamento e consumo e não de produção, a cidade distanciou-se, necessariamente dos ecossistemas naturais, para tornar-se anti-natureza por excelência (BRANCO, 1999). Juntamente com o crescimento demográfico e com o aumento de produção e de consumo, cresce também, a pressão sobre o ambiente. Aparecem, em especial, de modo inesperado, conseqüências ambientais tão amplas quanto maior for o tempo da modificação do ambiente.

Deve ser enfatizado que os sócio-ecossistemas urbanos são os grandes geradores de demandas de recursos naturais no mundo, e que cada indivíduo tem um papel dentro desse metabolismo. Os atos e decisões de consumo (água, energia elétrica, combustível, alimentos, serviços, etc.) geram impacto, que podem ser minimizados por racionalização de uso (reutilização, reciclagem, redução, substituição, eliminação), ou aumentados (desperdício, opulência) (DIAS, 1997).

A adaptação cultural por meio das escalas de produção e de consumo (satisfação crescente das necessidades), associada ao gradual crescimento demográfico, conduz ao esgotamento dos recursos naturais e à diminuição da recepção do ambiente às modificações antrópicas. 0 desaparecimento das habilidades de adaptação da população para o ambiente urbano possibilitou o surgimento dos estados patológicos. Hoje, grande parte da população mundial vive nas cidades. A maioria delas em ambientes residenciais de conglomerados, dificultando, assim, em alto grau, as relações interpessoais, o acesso às condições dignas de sobrevivência e à melhor qualidade de vida. O referido crescimento das necessidades humanas provém da escala de exigências do indivíduo, mas também de causas subjetivas.

No ser humano, existem dois modos de acumulação de informações: biológico (as estruturas bioquímicas) e cultural (o conhecimento). Como ser biológico, participa da natureza, mas como ser social, organiza-se, produzindo relações ímpares com ela. Assim, ao fazer uso dos recursos naturais para sua sobrevivência, provoca alterações no ambiente que poderão levá-lo a sua própria extinção. Há, também, dois modos de transmissão de informações entre as gerações humanas, que são: genético e cultural. O primeiro age, sempre, ainda fora da nossa consciência; o segundo pode ser, também, direcionado conscientemente no processo da educação. A consciência forma, na maioria da população, as condições de existência em escala de sociedade e indivíduo.

Desenvolvem-se juntamente com crescimento da civilização e o avanço migratório, o desenvolvimento econômico e industrial. A agricultura e pecuária assemelham-se, sob o ponto de vista da produtividade e dos métodos usados, à indústria. Os resultados colaterais desse desenvolvimento planejado são os aumentos de estresse e da poluição. O aumento simultâneo da 
sensibilidade do organismo sobre o ambiente e o aparecimento de elementos nocivos, condiciona o aumento de ameaças à saúde ambiental.

A cidade, embora meio ambiente, não chega a constituir um ecossistema verdadeiro, uma vez que não compreende uma atividade de produção ou fixação de energia primária (ODUM, 1988). A cidade se constitui, ao contrário, no destino final dos produtos de áreas externas; florestais, agropecuárias, marinhas ou de mineração, continuamente exploradas e provedoras de um fluxo contínuo de energia e matéria: combustíveis, matérias-primas e alimento. Estes, uma vez "processados" por meio da atividade industrial, comercial ou biológica, geram subprodutos na forma de resíduos sólidos, líquidos e gasosos que, de certa forma, condicionam o meio ambiente urbano conferindo-Ihe algumas de suas características e sobrecarregam, em geral, os sistemas finais de decomposição em um processo que se convencionou denominar de poluição (ALVES et al., 2009)

Indicam-se, atualmente, de modo frequente, a alteração e a devastação do ambiente natural, como as causas da perturbação da saúde. Essa devastação é fruto do insuficiente autocontrole cultural. É importante salientar que não só as grandes catástrofes socioeconômicas (fome mundial), mas também, os pequenos conflitos sociais e pequenas perturbações econômicas condicionam, de modo marcante, a diminuição do bem-estar e da saúde ambiental. O organismo humano é um indicador muito sensível de qualquer mudança que aconteça ao seu redor, tanto no setor da natureza, como no setor social.

\section{A relação cultura e natureza}

As relações entre a natureza e a cultura, desde a Antiguidade clássica, vêm sendo observadas por intermédio de uma série de diferenciações que, em última instância, buscam celebrar as singularidades do prodígio humano frente aos desígnios da natureza. Apesar de permeadas por interpretações que, de certa forma, tendem a tratar essas duas acepções como categorias antagônicas, as concepções de natureza adquiriram um sentido particular no engendramento da sociedade humana. A acepção de natureza, ora rivalizando com a arte, ora competindo com a técnica, tendeu a cristalizar-se na historiografia como pressuposto da negação das conexões do homem com o estado natural (PELEGRINI, 2006).

O homem é um produto da natureza. Na sua história nota-se a busca pelo controle dos recursos naturais. Este controle, o homem exerce de vários modos, atingindo o equilíbrio natural e as leis da natureza. Nesse processo, esquece que é produto biológico e uma parte inseparável da natureza primitiva e da transformada. Sendo parte integrante, depende da natureza como organismo, produto da evolução biológica e da adaptação cultural às condições ambientais. Se não as encontra, ele as produz artificialmente.

Assim, se existe algo de intrinsecamente humano é a cultura. Cultura entendida aqui como dotação de significados, ou seja, atribuição de sentidos às ações, sensações, emoções, e a todas as relações imediatas que os humanos, estabelecem com o mundo material - orgânico ou construído. Neste sentido, pode-se pensar a relação natureza e cultura, na qual a natureza é um Outro que, ao mesmo tempo, inclui o humano sem subsumi-lo completamente ao universo biológico não humano. Assim, nesta posição de seres híbridos, ou seja, ao mesmo tempo semelhantes e diferentes de uma natureza estritamente biológica, nascem as condições para um permanente diálogo caracterizado pela tradução cultural do mundo natural. Neste diálogo, inscrevemos as 
condições naturais em que vivemos em nosso mundo de significados, transformando a natureza em cultura, conhecimento, fonte de vida material e simbólica, ao mesmo tempo em que reencontramos a natureza em nós (CARVALHO, 2004).

O ambiente é feito dos "olhos do ser", social, produto da relação entre os homens, processado pela história. No interior do corpo aparentemente apenas físico do ambiente, a história social se apropria dos demais "conteúdos de corpo" para que se faça o ambiente (HISSA, 2002). Quando, por algum motivo, pronunciamos a palavra natureza nos vêm à mente a ideia de um ambiente natural, provavelmente intocado e em equilíbrio e, portanto, separado do ser humano. Todavia, tudo o que a humanidade realiza é, por conseguinte natureza. Sabemos ainda, que tantas foram às sociedades quanto os conceitos de natureza, haja vista cada uma dessas sociedades se apropriar ou se relacionar com a natureza de forma diferenciada (CARVALHO, 1999). O relacionar pressupõe um distanciamento, separação e alienação, ainda que de modo inconsciente, mas presente em todas as sociedades que já existiram na história da humanidade (ROCHA \& MOTA, 2011).

As sociedades humanas diferem amplamente entre si em termos de cultura, qualidade de vida e condições ambientais, e na percepção do significado dessas diferenças (CAMARGO, 2003). É preciso evidenciar, cada vez mais, as especificidades étnicas e culturais de cada civilização e dos caminhos de desenvolvimento das sociedades do mundo. Se a humanidade, no seu todo, fosse uma civilização urbana-industrial, o aumento da crise do modelo atual da nossa civilização poderia levar a uma catástrofe em escala global. Um determinado modelo cultural, mesmo que aceito globalmente, somente seria válido, sob o ponto de vista de determinada época, de região e do sistema sócio-político.

As culturas da Europa Contemporânea, provindas da civilização e da filosofia grega, das crenças judaicas e cristãs, recomendavam ao homem o domínio sobre a natureza. Com isso, essas ideologias, fundadas sobre as premissas de migração, de multiplicação e de submissão da natureza do homem, promoveram a crise ecológica da era contemporânea (THOMAS, 1989). Entretanto, existem outras civilizações e culturas, as quais se assemelham bem mais ao mundo vivo. Por isso, nessa pluricultura e pluralidade de formas biológicas e sociais do homem que pode haver esperança para o futuro.

A emergência de uma "consciência preservacionista" na esfera ambiental se consolidou na década de 1980. O movimento em prol do direito e da proteção ao meio ambiente se irradiou por meio da comunidade científica e acabou se difundido entre organizações não-governamentais, que passaram a reivindicar melhor "qualidade de vida" no planeta. Entretanto, a questão da preservação do patrimônio natural vem suscitando polêmicas desde longa data. Para as correntes naturalistas do século XIX, a maneira mais adequada de garantir a proteção das áreas naturais residia em afastá-las do homem. Esse entendimento, por sua vez, consistia em uma reação à corrente culturalista, segundo a qual a natureza representava uma ameaça de volta à condição "selvagem" do homem (FONSECA, 1996).

A estratégia parece ser o desenvolvimento controlado, baseado nas tradições étnicas e locais e regionais e, que busca pela necessidade dos conhecimentos contemporâneos as características do determinado ambiente. O homem com sua cultura é uma parte dos ecossistemas. A cultura não pode ser colocada acima da natureza, pois acaba destruindo-a. A cultura deve ser, juntamente com a natureza, parte do sistema comum, tendo em vista o futuro do planeta. Devem-se concentrar esforços para conservar as características da cultura, a plurifacialidade de suas manifestações e de suas formas, conforme o mesmo princípio de 
preservação das espécies animais e vegetais, considerando-os como produtos da evolução, selecionados durante milhares de gerações.

Podemos afirmar que o homem não entra em cena como os animais e as plantas, os quais, realmente, dependem da ambiência. O homem surge com uma característica especial: a de ator, como ser cultural. Cultura, entendendo-se como uma criação do homem transmitida pela tradição ou, então, como resposta dada pelo homem ao meio ambiente (ULLMANN, 1983). Independentemente de crença religiosa, política e nível social, todos são convocados a refletir sobre a responsabilidade de sua atitude, no mundo de hoje, que é o mundo de nossos descendentes.

Geertz (1989) considera que homem e cultura evoluem juntos, a cultura sendo constituinte da natureza humana. Apropriando-se dessa ideia, Wagner (1981) busca desconstruir a alegoria dos animais que se tornam homens. Ele faz notar que, em sua evolução, o homem não se distanciou de sua "natureza" e também não se tornou "mais cultural" do que seus antepassados. A construção de modelos processa-se segundo duas direções: os homens são levados a interpretar a natureza como uma elaboração cultural e a ver a cultura como uma transformação da natureza (LEACH, 1985).

Mais do que nunca a natureza não pode ser separada da cultura e precisamos aprender a pensar "transversalmente" as interações entre ecossistemas, mecanosferas e Universos de referência sociais e individuais (GUATTARI, 1997). O diálogo entre a sociedade e a natureza, tomado como uma interação permanente, em que as partes se modificam mutuamente, possibilita uma compreensão dinâmica dessa relação. Ao privilegiar a compreensão do humano nas interações com a natureza, segundo uma concepção interpretativa, de evidenciar os horizontes de sentidos históricoculturais que configuram, em um tempo específico, as relações de determinada comunidade humana com o meio ambiente (CARVALHO, 2004). A dissolução da dicotomia natureza/cultura além de implicar na dissolução das fronteiras entre os domínios da arte e da ciência, também implica na reformulação da oposição entre viver (ligado à relação do sujeito com o mundo exterior) e pensar (ligado a seu mundo subjetivo). Nesse sentido, a dissolução da dicotomia em questão contribui para uma abordagem mais complexa e reflexiva da relação cultura/natureza, ou seja, mais atenta à especificidade de sua forma de constituir e apreender o mundo, historicamente contextualizada e, portanto dinâmica e sujeita a mudanças (JACQUES, 2010).

Os principais entraves a um desenvolvimento sustentável global estão interligados entre si, alguns diferem ou são mais ou menos evidentes de acordo com as diferentes regiões do globo. Entre os principais entraves culturais estão as diferentes maneiras de os diferentes povos relacionarem-se com a natureza e utilizarem os recursos naturais; os diferentes valores e crenças dos diferentes povos - que influenciam o modo de conceber conceitos como qualidade de vida, qualidade ambiental, necessidades, prioridades, progresso, desenvolvimento, entre outros; as crenças e os valores antropocêntricos profundamente enraizados no mundo ocidental; a existência de culturas hostis a qualquer tipo de aproximação de outras comunidades (CAMARGO, 2003).

Tanto a poluição quanto a depredação de recursos - as duas grandes áreas em que é possível agrupar todos os problemas ambientais - podem ser relativizados pela cultura. "O que é sujo ou llimpo?"; "quando uma espécie ou recurso está em extinção?" - são perguntas cuja resposta depende de critérios relativos à cultura (FOLADORI \& TAKS, 2004). Margulis (2001) salienta que nossas decisões não influenciarão o planeta todo, mas somente a nossa civilização. Afirma que nenhuma cultura humana poderia acabar com a vida na Terra e que precisamos nos 
libertar da arrogância específica da nossa espécie. Ressalta que os seres humanos são apenas uma parte recente de uma gigantesca e antiga totalidade e que a Terra sobreviverá às destruições provocadas pelo homem. Segundo ela, não existem provas de que tenhamos sido 'escolhidos', e que não podemos dar um fim à natureza; só representamos uma ameaça a nós mesmos.

\section{A problemática ambiental}

Ao longo da história, inúmeros problemas ambientais, associados às precárias condições sanitárias das cidades afetaram a saúde e o bem-estar das pessoas e causado consideráveis prejuízos às atividades econômicas. Lora (2000) aponta dois momentos emblemáticos de intensificação da degradação do meio ambiente pela atividade humana. O primeiro está relacionado com o processo de concentração urbana e industrialização, ocasionados pela Revolução Industrial do século XIX, e o segundo ao 'boom' econômico dos Países industrializados e a consequente explosão do consumo, verificado após a segunda guerra mundial.

Apesar dos graves problemas ambientais do século XIX relacionados à poluição industrial, um dos motivos pelos quais a preocupação ambiental não surgiu naquela época de forma mais explícita foi o fato de a degradação ambiental afetar principalmente os trabalhadores, sendo somente no século XX que esses problemas alcançaram também as classes mais favorecidas (LAGO \& PÁDUA, 1984). A percepção dos problemas ambientais, generalizada a partir dos anos 1970, quando surgem, com mais frequência, em âmbito internacional, manifestações ecológicas e questionamentos relacionados aos impactos das atividades humanas sobre a natureza e sua interface com os aspectos econômicos e sociais, tem gerado o uso e a disseminação de diversos termos para identificar problemas e soluções de ordem teórica e prática: ecodesenvolvimento, desenvolvimento sustentável, sustentabilidade, degradação ambiental, preservação do meio ambiente etc. (LIMA \& RONCAGLIO, 2001).

Outro marco importante da década de 70 foi a emergência de uma nova maneira de perceber os problemas ecológicos, a Ecologia Profunda. Segundo Capra (1996), a ecologia profunda, além de uma escola filosófica específica, teve e tem a dimensão de um movimento popular global. Embora surgida na década de 1970, tem hoje defensores por todo o mundo e é atualíssima em relação aos problemas da nossa época (CAMARGO, 2003). A consciência de que os recursos da natureza não são ilimitados coloca em discussão o modelo de natureza servil e o modelo de desenvolvimento baseado no antropocentrismo predatório. Nesse contexto, homem e natureza passam a fazer parte de um mesmo corpo, encadeados no ciclo das relações mútuas (MARQUEZ, 2008). O problema ambiental reside no espaço urbano, numa ideia de redimensionamento dos hábitos cotidianos e na compreensão do seu lugar na prática ampla do mundo.

A emergência do paradigma ambiental, resultante da própria crise ambiental, da inquietação ética gerada no interior da cultura moderna, é parte integrante da transição contemporânea, por meio da qual é interrogada a natureza do conhecimento e, particularmente, a disciplina. Retoma-se à reflexão: as questões ambientais, como todos os problemas de interesse da ciência, são complexas e demandam leituras transdisciplinares (HISSA, 2008). Embora a problemática ambiental exija uma integração de conhecimentos e uma retotalização do saber, as aproximações sistêmicas, holísticas e interdisciplinares, limitadas à reorganização do saber disponível, são insuficientes para satisfazer esta demanda de conhecimentos. 
O relatório Our commom future (Nosso futuro comum) - também conhecido como Relatório Brundtland, publicado em 1987, registrou os sucessos e as falhas do desenvolvimento mundial. Entre os resultados positivos estavam a expectativa de vida crescente, a mortalidade infantil decaindo, o maior grau de alfabetização, inovações técnicas e científicas promissoras e o aumento da produção de alimentos em relação ao crescimento da população mundial. Por outro lado, apontou uma série de problemas, como aumento da degradação dos solos, expansão das áreas desérticas, poluição crescente da atmosfera, desaparecimento de florestas, fracasso de programas de desenvolvimento, entre outros (FRANCO, 2000). Esse relatório parte de uma visão complexa das causas dos problemas socioeconômicos e ecológicos da sociedade global. Ele sublinha a interligação entre economia, ecologia, tecnologia, sociedade e política e chama também a atenção para uma nova postura ética, caracterizada pela responsabilidade tanto entre as gerações quanto entre os membros contemporâneos da sociedade (BRÜSEKE, 1998).

Segundo o relatório Brundtland, a definição de Desenvolvimento Sustentável é aquele que atende às necessidades do presente sem comprometer a possibilidade de as gerações futuras atenderem a suas próprias necessidades (BRUNDTLAND, 1991). Essa definição, representa para vários autores, o consenso possível, já que não entra no mérito dos modelos e alternativas de desenvolvimento ou das relações sociais, mas enfatiza o compromisso intergeneracional, ao procurar garantir a possibilidade do futuro (COSTA, 2008).

Nos últimos 30 anos do século XX e nos primeiros anos do século XXI, a questão ambiental tem ganhado relevo no cenário político, econômico e intelectual mundial. As discussões acerca das temáticas relacionadas ao ambiente, bastante diversificadas, foram ainda mais estimuladas pela globalização (ROCHA, 2008). Se a consciência ambiental cresceu consideravelmente a partir da segunda metade do século $\mathrm{XX}$, a percepção dos problemas ambientais ocorreu de modo diferenciado ao longo do tempo. Numa primeira etapa, ocorre a percepção dos problemas ambientais localizados. Numa segunda etapa, a degradação ambiental é percebida como um problema generalizado, porém confinado aos limites territoriais dos Estados nacionais. Numa terceira etapa, a degradação ambiental é percebida como um problema planetário e que atinge a todos (CAMARGO, 2003).

Em contraste com o desenvolvimento econômico convencional, o desenvolvimento sustentável é indissociável do desenvolvimento global da sociedade, pois depende de mudanças econômicas, sociais, culturais e ecológicas. Costa (2008) enfatiza o avanço da ecologia política na reflexão sobre as relações natureza-sociedade, as causas da degradação ambiental e a necessidade de repensar o próprio conceito de desenvolvimento. Hardin (1968) afirma que a maioria dos problemas ambientais provém de uma causa única: a utilização inadequada de recursos que são de propriedade comum, tais como o ar, a água, a maioria das espécies animais e as áreas verdes não têm um proprietário definido e ninguém se responsabiliza pelas obrigações de preservação desses recursos.

Com a integração dos aspectos ecológicos na lógica capitalista, ocorre a necessidade do capitalismo transformar a questão ecológica - um entrave para seu crescimento - em uma fonte de lucro, tornando-a uma mercadoria e comercializando-a a partir de uma nova ordem mundial. O capital se reestrutura e se racionaliza para recuperar sua capacidade de exploração. De fato, é muito mais interessante para os condutores do capital a produção de uma leitura fragmentada da crise ambiental: fragmentando a natureza, fragmentam-se os sujeitos e a resistência que deles poderia brotar (SANTOS, 2002).

A questão da preservação ambiental ganhou campo quando o homem começou a perceber que estava perdendo boa parte de um patrimônio natural de valor inestimável, o qual ele não é 
capaz de criar, de reconstruir nos moldes como a natureza o faz. Diante da ameaça de extinção dos recursos naturais, das espécies vivas, dentre as quais a própria espécie humana, o homem começa a voltar-se para as questões que afetam de maneira negativa o meio em que vive (SCHONARDIE, 2005). O problema ecológico humano é que todas as atividades que denominamos "desenvolvimento" tendem a implicar interferência nos ecossistemas naturais. Os recursos renováveis não têm poder para se autoproduzirem na velocidade exigida pela lógica do crescimento acelerado. Por outro lado, os ecossistemas não têm capacidade de absorver indefinidamente os detritos gerados pela sociedade industrial (CAMARGO, 2003).

Capra (1996) argumenta que os problemas socioambientais de nossa época precisam ser percebidos como diferentes facetas de uma única crise, uma crise de percepção, que advém do fato de a maioria dos seres humanos concordar com conceitos de uma visão de mundo obsoleta, uma percepção da realidade inadequada para lidarmos com nosso mundo atual superpovoado e globalmente interligado.

\section{Modos de produção e consumo}

Com a racionalidade crescente no século XIX, que atribuiu ao homem a tarefa de dominar/explorar a natureza, aliada ao também crescente processo de industrialização, o desenvolvimento centrado na ciência e Tecnologia ( $C$ \& T) passou a ser visto como sinônimo de progresso (ANGOTTI \& AUTH, 2001). Os níveis de produção e consumo que passam a vigorar a partir das décadas de sessenta e setenta, combinados ao crescimento populacional vertiginoso observado a partir de então, levaram as sociedades a uma nova percepção do mundo em que vivemos, um mundo finito em recursos naturais e com um meio ambiente, belo, mas frágil, passível de destruição (RIBEMBOIM, 1997).

A produtividade e a produção incorporam velocidades progressivamente mais intensas. Todos os bens incorporam os ritmos de sua própria produção que, também, passam a produzir valores. Antes mesmo da produção de bens, a produção em série ainda fabrica os desejos de consumo progressivamente mais diversificados, cada vez mais distantes do que necessitam as vidas dignas (BAUDRILLARD, 1975). Para assegurar um padrão de vida relativamente sustentável para as futuras gerações, é preciso que, de algum modo, seja preservado o patrimônio natural. Nessa busca, surgem movimentos chamados "socioambientais", "socioeducativos" ou de "conscientização" para reduzir, reutilizar, reciclar e recuperar, minimizando os impactos surgidos pela utilização "infinita" dos recursos naturais.

O uso de materiais recicláveis, de alternativas energéticas renováveis e limpas, de eliminação de desperdícios, tudo isso é relevante para os novos padrões requeridos. Mudar o padrão de consumo é, antes de tudo, mudar o próprio comportamento das pessoas. Isto decorre da mudança de enfoque sobre o problema da poluição. Antes, as atenções centravam-se unicamente no lado da produção. As fábricas eram a grande fonte da degradação ambiental, isentando o consumidor de qualquer responsabilidade.

A mudança do enfoque, agora também centrado no consumidor, decorreu da observação de que, quem demanda o produto também polui, o consumidor e, portanto, nada mais justo de que a responsabilidade seja solidária. Portanto, ambos, produtores, distribuidores, importadores e consumidores, são os responsáveis pela poluição. É difícil separar a atividade de produção da atividade de consumo quando o objetivo é o consumo, pois investimento nada mais é do que uma 
forma de consumo futuro (WEITZMAN, 1976). Dessa forma é exigido do consumidor mudanças nos seus hábitos e uma maior compreensão para o fato de que os recursos ambientais são esgotáveis e estão se tornando cada vez mais escassos.

Em contrapartida, a responsabilidade da empresa sobre o produto vai muito além de seus estabelecimentos, envolvendo aspectos como embalagem, transporte, matéria-prima-usada, reciclagem e biodegradabilidade de resíduos. A mudança nos padrões de produção e consumo implica no aumento do nível de informação da população, conscientização das pessoas, redução no desperdício, desenvolvimento tecnológico, responsabilidades compartilhadas, reciclagem, e acima de tudo, na mudança do padrão comportamental.

Além do crescimento do consumo advindo do acúmulo de capital e dos avanços tecnológicos e da melhoria dos processos de produção, dois fenômenos demográficos foram particularmente importantes para o aumento do consumo agregado: o crescimento populacional e a rápida urbanização, ocorridos na segunda metade do século XX. Sendo assim, o paradigma atual de decisão familiar, associado à redução da mortalidade infantil e dos avanços da medicina, resulta em taxas extremamente altas de crescimento populacional nas economias menos desenvolvidas (FERRAZ, 1991).

Paralelamente ao crescimento populacional, outro fenômeno global é o da urbanização. 0 fenômeno da urbanização no mundo em desenvolvimento não se desenvolve de forma equilibrada sobre o território, tampouco segue os mesmos padrões. Contudo, a concentração crescente da população em grandes aglomerações, o crescimento acelerado de cidades milionárias, a proliferação de megacidades são efeitos desse processo e parecem caracterizar uma tendência mundial (NICO, 2010).

A urbanização contribui em muito para o aumento da produção e do consumo, à medida que permitem aos indivíduos e as empresas terem acesso as economias de aglomeração (SOUZA, 1981). Como as empresas e os indivíduos estão mais próximos uns dos outros, torna-se mais fácil o acesso aos mercados e a produção e, o consumo em quantidades pode permitir um custo utilitário menor. É importante ressaltar que a urbanização não é algo negativo, entretanto, se ela ocorrer de forma acelerada e desordenada, produz uma série de subprodutos indesejáveis vivenciados por nós a cada dia: poluição, violência urbana, congestionamentos, exclusão social e estresse (LEIPERT, 1986).

Em encontros internacionais sobre produção e consumo sustentáveis, o tema energético vem sendo considerado de forma sempre crescente, e encontram-se estreitamente relacionados tanto com as questões internas nacionais de eficiência econômica e poluição, quanto com os problemas globais de mudanças climáticas, chuva ácida e questões transfronteiriças (MORAIS \& BORGES, 2010). Durante a Conferência das Nações Unidas para o Meio Ambiente e Desenvolvimento, mais conhecida como a ECO/RIO 92, o tema "mudança dos padrões de consumo" foi levantado e discutido a partir do reconhecimento de que o desenvolvimento sustentável só poderia ser atingido se fossem, urgentemente, reduzidos os impactos da produção e consumo e do crescimento populacional vigentes (CONFERÊNCIA DAS NAÇÕES UNIDAS SOBRE MEIO AMBIENTE E DESENVOLVIMENTO, 1996). O crescimento do consumo merece uma atenção cada vez maior por parte das autoridades públicas em todo o mundo. Nos últimos 55 anos, a economia global praticamente quintuplicou, o consumo de grãos, carne e água triplicou e o consumo de papel cresceu em mais de seis vezes. O uso dos combustíveis fósseis aumentou em quatro vezes, assim como o nível de emissões de $\mathrm{CO}_{2}$, principal gás responsável pelo efeito estufa (BROWN et al., 1996). 
Em contrapartida, as políticas públicas que buscam a mudança dos padrões de produção e consumo devem estar relacionadas com aspectos econômicos, sociais e ambientais do desenvolvimento sustentável. Um enfoque integrado do ponto de vista ambiental e econômico, tanto pelo lado da demanda (consumo), quanto pelo lado da oferta (produção), é a forma mais eficaz para o atendimento da condição da sustentabilidade (SICHER et al., 2007). Para Montibeller (2004), muitos dos problemas decorrentes de padrões insustentáveis de produção e consumo são devido ao fato de que os bens e serviços ambientais encontram-se subavaliados e, dessa forma, tendem a ser desperdiçados, quer seja quando utilizados como insumos no processo produtivo ou quando consumidos diretamente pelos indivíduos.

Apesar das dificuldades, à medida que a ideia da sustentabilidade se difunde, aumenta o interesse pelo conceito da ecoeficiência na gestão e pela implementação de políticas ambientalmente sustentáveis. O conceito de ecoeficiência significa uma estratégia econômica, ambiental e técnica, integrada aos sistemas de produção e consumo. Ecoficiência é um termo relativamente novo: utilizado pela primeira vez pelos pesquisadores suíços Schaltegger e Sturm, em 1990 (SALGADO, 2004). Ao ler pela primeira vez a palavra, logo se pensa que a Ecoeficiência seja somente "eficiência ecológica", causando a impressão de que sejam apenas gastos para diminuir os impactos ambientais. Porém, isso não é totalmente verdade, já que a Ecoeficiência busca segundo a definição feita pelo World Business Council for Sustainable Development - WBCSD (LEHNI, 2000), é a oferta de bens e serviços a preços competitivos que satisfaçam as necessidades dos clientes e, ao mesmo tempo, reduzam os impactos ambientais causados pela sua produção e pela utilização em todo o seu ciclo de vida, respeitando a capacidade de sustentação estimada para o planeta Terra: produzir mais com menos.

A ecoeficiência é muito importante estrategicamente para uma empresa, já que permite que sejam reduzidos gastos com matérias-prima, energia e água, promove também a prevenção de acidentes ambientais e suas consequentes sanções, além de conquistar mais consumidores. $O$ aumento da eficiência pode trazer significativas melhorias econômicas e ambientais e pode ser alcançado pela redução do uso de materiais e pelo aumento da durabilidade do produto, utilizando-se tecnologias já disponíveis, reciclagem e redução de desperdícios (BRANDSMA \& EPPEL, 1997).

A Produção Mais Limpa $(\mathrm{P}+\mathrm{L})$ visa melhorar a eficiência, a lucratividade e a competitividade das empresas, enquanto protege o meio ambiente, o consumidor e o trabalhador. $O$ principal ponto desse conceito é a necessidade de desenvolver mais e mais os processos de produção, passo a passo, com a análise contínua do processo, melhorando e otimizando o processo antigo e/ou implementando total ou parcialmente novos processos (GIANNETTI \& ALMEIDA, 2006).

Torna-se necessária a mudança do modelo usado na produção de produtos, nos serviços e da forma como ocorre o consumo. E, especialmente, a questão do consumo está associada a outro estilo de vida: consumir de forma diferente, privilegiando os produtos duráveis e não os descartáveis; a reutilização e reciclagem dos resíduos; priorizando o importante e não o supérfluo; e valorizando a moderação e não o excesso. É absolutamente urgente que façamos essa transição para uma sociedade mais sustentável. Além de políticas públicas e soluções tecnológicas capazes de minimizar os impactos da previsível explosão de consumo, é preciso investir e produzir bens simbólicos no redirecionamento das aspirações da sociedade como um todo. É necessário um esforço urgente e sem precedentes para dissociar o sentido de qualidade de vida ao aumento contínuo do consumo. Esta equação, que ainda move o crescimento da sociedade, é incompatível com o objetivo de compartilhar os benefícios do consumo com toda a sociedade e de respeitar os princípios da sustentabilidade ambiental. 


\section{Ecologia industrial}

Desde o inicio da civilização as atividades humanas produzem alterações na Terra, mas o que está em questão é a velocidade e a escala da destruição ambiental e social provocadas pelas interferências resultantes de empreendimentos econômicos nos últimos 50 anos (GRIMBERG, 2005). No início da história da humanidade, a produção, por mais primitiva que fosse, era sempre constituída por um sistema aberto, com fluxo linear de materiais. $\mathrm{Na}$ era pré-industrial, a antroposfera poderia ser considerada em equilíbrio com os demais elementos do sistema natural, e a humanidade, considerada parte do ecossistema natural (GIANNETI \& ALMEIDA, 2006). Com o aumento da população mundial, o descarte dos resíduos se tornou cada vez mais problemático. Evidentemente, o processo de degradação ambiental tem início na produção.

O sistema de produção econômico é um subsistema de um ecossistema finito, no qual a economia vive baseada na importação de matéria de baixa entropia (recursos naturais) e a exportação de matéria com alta entropia (resíduos). Em função da crescente importância dos problemas ambientais nos modelos econômicos e de desenvolvimento, se torna importante o estudo do comportamento dos materiais e substâncias dentro da economia, pois existe uma relação direta de determinados problemas ambientais com estes fluxos (SABLOWSKI, 2008). O capitalismo, tal qual vem sendo praticado, é uma aberração lucrativa e insustentável do desenvolvimento humano. O que se pode designar como "capitalismo industrial" não se ajusta aos seus próprios princípios de contabilidade. Ele liquida seu capital e chama isso de renda. Descuida de atribuir qualquer valor ao mais importante capital que emprega: os recursos naturais e os sistemas vivos, assim como aos sistemas sociais e culturais que são a base do capital humano (HAWKEN et al., 2011).

A economia ecológica e a ecologia industrial representam dois meios pelo qual o ambiente natural é incorporado nos processos de tomada de decisão industrial (EGRI \& PINFIELD, 1998). A ecologia industrial está preocupada com os meios de alcançar sistemas de produção ambientalmente sustentáveis (HAWKEN, 1993) ao propor que o impacto dos sistemas industriais no ambiente natural pode ser minimizado pela adoção dos princípios de gestão da qualidade total ambiental para produto e desenho de processo (CALLENBACH et al., 1993).

A ecologia industrial emergiu do entendimento de que os métodos tradicionais de despoluição denominados end of pipe (fim do tubo) não eram suficientes. Algumas companhias, por muitos anos, testaram diferentes estratégias de prevenção de poluição e, entre estes métodos, observam-se a análise de ciclo de vida, a gestão da qualidade e outros. A idéia central atual é integrar conceitos existentes em metodologias end of pipe e de prevenção à poluição, sob a perspectiva da ecologia industrial e do metabolismo industrial. Atualmente, a ecologia industrial entende que existem variados ecossistemas industriais com diferentes padrões de interação com a biosfera (ERKMAN et al., 2005).

A premissa básica da ecologia industrial é não considerar as atividades de uma planta industrial de maneira isolada, mas sim como um ecossistema industrial que funciona dentro do ecossistema natural, ou seja, da biosfera. Assim como o ecossistema natural, o sistema industrial consiste fundamentalmente em fluxos de materiais, energia e informação, além de depender de recursos e serviços fornecidos pela biosfera. No contexto da ecologia industrial, o termo "industrial" alude a todas as atividades humanas que têm lugar na moderna sociedade tecnológica, como as atividades agrícolas e de serviços, por exemplo, atividades turísticas e serviços de saúde. (ERKMAN et al., 2005). 
Pela analogia do sistema industrial com os ecossistemas, a ecologia industrial resgata a ideia de que a antroposfera é parte da biosfera e que somente pode existir em equilíbrio dinâmico com as outras partes do sistema, a atmosfera, a hidrosfera e a litosfera. Os princípios da ecologia industrial fornecem uma base para o desenvolvimento de um sistema industrial que vise a sustentabilidade (GIANNETI \& ALMEIDA, 2006). Seguindo a analogia, a ecologia industrial utiliza a ideia de ecossistemas industriais como um modelo para a restruturação dos sistemas econômicos, tendo como base a integração das atividades e a reciclagem de materiais. O ecossistema industrial se caracteriza como uma cadeia de extratores de matérias-primas do ambiente, transformadores de materiais primários, fabricantes de componentes, montadores de produtos, consumidores de bens e serviços e recicladores.

A proposta da ecologia industrial não é somente a "ecoindústria", sinal da preocupação da indústria com a proteção do meio ambiente. Também não são os produtos "verdes" ou a reciclagem parcial dos detritos. Mas sim, a reconfiguração completa dos processos industriais, desde a regulação dos fluxos de energia, matérias primas e produtos a partir da reutilização racional dos detritos (ROSNAY, 1997). A ecologia industrial funciona a partir de conceitos tais como a ecoeficiência, a circulação de recursos, o ecodesign e a Análise do Ciclo de Vida (ACV). Estes conceitos estabelecem requisitos e restrições que os processos industriais, materiais e os produtos devem ter para que possam infligir impactos mínimos ao meio ambiente.

Por outro lado, a ecologia industrial, se encarada sob a ênfase histórica no aproveitamento de resíduos como insumos, mostra-se mais efetiva na identificação de fluxos de materiais dos grandes sistemas do que propriamente na efetivação dessa reciclagem sistêmica. Ela visa diminuir a utilização de recursos naturais por meio da desmaterialização, que é a redução relativa da quantidade de material por unidade de produto, e do aumento da circulação de material no sistema antes do descarte final. Devido à sua natureza multidisciplinar, a pesquisa nesta área deve integrar vários conceitos e várias áreas do conhecimento, como por exemplo, a gestão ambiental, a contabilidade ambiental e o direito ambiental, com a finalidade de desenvolver/produzir produtos, resíduos e subprodutos, cujo impacto no meio ambiente seja menor (GIANNETI \& ALMEIDA, 2006).

\section{Gestão ambiental nas empresas}

A gestão ambiental exige uma nova atitude dos empresários e administradores, de modo a incluir as questões ambientais em suas decisões e a adotar concepções administrativas e tecnológicas que contribuam para ampliar a capacidade de suporte (BARBIERI, 2007). Trata-se da empresa alterar sua interpretação dos problemas de poluição como um custo para enxergá-la como um investimento ambiental.

As principais vantagens do Sistema de Gestão Ambiental (SGA) são a minimização de custos, de riscos, a melhoria organizacional e a criação de um diferencial competitivo. Os custos são reduzidos pela eliminação de desperdícios, racionalização de recursos naturais, humanos, físicos e financeiros e, pela conquista da conformidade ambiental ao menor custo. A implementação do SGA possibilita também a precisa identificação dos passivos ambientais e fornece subsídios ao seu gerenciamento. Esses procedimentos promovem a segurança legal, a minimização de acidentes, passivos e riscos por meio de uma gestão ambiental sistematizada que permite a sua integração à gestão dos negócios. Essa atitude melhora a imagem da empresa, 
aumenta a produtividade, promove novos mercados e, ainda melhora o relacionamento com fornecedores, clientes e comunidade (ANDREOLI, 2002).

$\mathrm{Na}$ economia globalizada dos dias atuais, as organizações estão cada vez mais sendo pressionadas a demonstrar um gerenciamento adequado em suas estruturas ambiental, social e econômica. Isso vem em decorrência de uma consciência popular crescente sobre os danos causados ao meio ambiente e à saúde de comunidades, ao longo da evolução dos processos produtivos, além das enormes desigualdades sociais existentes ao redor do planeta (POMBO \& MAGRINI, 2008). A responsabilidade ambiental da empresa é raramente voluntária, ocorrendo mais frequentemente em resposta a enérgicas regulamentações e à pressão do consumidor (SCHNAIBERG \& GOULD, 1994).

Ao longo dos últimos 50 anos, uma série de instrumentos foi sendo desenvolvidos para atender a maneira como a indústria entendia que deveria tratar o meio ambiente, como exemplo, a avaliação de risco, a análise da intensidade de material, a avaliação do ciclo de vida, o sistema de gestão ambiental, os relatórios de comunicação ambiental, as certificações ambientais, programas de prevenção à poluição, a Produção Mais Limpa, a ecologia industrial (LIMA, 2008). Há uma tendência mundial dos investidores buscarem, para aplicar seus recursos, não só em empresas rentáveis, mas também naquelas que são consideradas sustentáveis e socialmente responsáveis. Desde a década de 80 , houve mudanças socioeconômicas que fizeram com que muitas empresas entendessem a necessidade de realizar atividades que não estivessem diretamente voltadas para a maximização do lucro e buscar um equilíbrio entre o crescimento econômico e o desenvolvimento humano (RAZZOTO, 2009).

Com relação ao panorama brasileiro, apesar de o meio empresarial ainda considerar problemas ambientais como secundários (SEIFFERT, 2007), a partir de 1980, as organizações passaram a sofrer influência direta da regulamentação governamental, proporcionando, com isso, uma mudança progressiva em seu ambiente de negócios. Alguns países, visando identificar e promover produtos que não agredissem o meio ambiente começaram a criar símbolos ou rótulos ecológicos, chamados de selos verdes, como o conhecido "Selo Anjo Azul" (Alemanha, 1977), o Eco Mark (Japão, 1989) e o Environmental choice (Canadá, 1988). A partir do início da década de 1980 , surgiram as principais iniciativas de desenvolvimento de modelos de Sistemas de Gestão Ambiental, destacando-se: Responsible Care Program, STEP (Strategies for Today's Environmental Partnership), BS 7750, EMAS (Eco-Management and Audit Scheme) e ISO 14001 (FOGLIATTI et al., 2011). A instituição e a adoção por diversas empresas em todo o mundo da série de normas ISO 14000 trazem uma nova perspectiva socioambiental. A ISO 14000 contém procedimentos gerenciais e de fabricação ambientalmente saudáveis, e recomenda métodos, tecnologias e uso de materiais que não sejam prejudiciais ao meio ambiente.

No Brasil, isto se fez sentir com a instituição do chamado "Protocolo Verde", segundo o qual os bancos públicos federais passaram a incorporar, de forma sistemática, a variável ambiental em seus processos de financiamento do setor produtivo. Este documento incorpora os princípios econômicos no tratamento ambiental e inicia, por assim dizer, uma nova etapa na política ambiental brasileira, conciliando desenvolvimento econômico e a proteção dos recursos naturais. Desse modo, a partir da aprovação da Política Nacional do Meio Ambiente, os recursos financeiros priorizam projetos que apresentam maiores características de auto-sustentabilidade e acarretarem menores danos ao meio ambiente (BRASIL, 1981).

O avanço rumo ao desenvolvimento sustentável se dá por meio da lógica do mercado, com a apropriação privada dos recursos naturais e da qualidade ambiental, prevendo a expansão do chamado "consumidor verde". Há uma progressiva incorporação da dimensão ambiental nas 
esferas de produção e da gestão dos recursos, introduzindo alguns mecanismos de controle de atividades poluentes, privilegiando atitudes de aproximação entre ecologia e crescimento econômico (LAYRARGUES, 2003).

As empresas bem sucedidas, além de atenderem as regulamentações governamentais sobre a questão ambiental, incluem o meio ambiente na sua filosofia empresarial e o adotam como uma questão estratégica para sobrevivência de seus negócios. Desse modo, considera-se que o marketing verde surge como uma ferramenta para auxiliar as organizações no processo de entrega de valor aos seus clientes com garantia de preservação ambiental (RAZZOTO, 2009). Por outro lado, é fato que o consumidor brasileiro valoriza cada vez mais às práticas de responsabilidade socioambiental das empresas, além de buscar informações sobre o assunto, todavia, está longe de incorporar esses valores em suas práticas cotidianas.

As empresas passam também a se preocupar com a quantificação dos recursos consumidos para evitar ou minimizar os impactos de suas atividades sobre o meio ambiente, esboçando sistemas de contabilidade ambiental para gerenciar seus ativos (bens e direitos reservados para a recuperação, a preservação, a proteção e o controle de meio ambiente) e passivos (gastos dispendidos com a prevenção ou a correção de problemas de natureza ambiental) ambientais (SCHOEMAKER \& SCHOEMAKER, 1995).

Quando consideramos a questão ambiental do ponto de vista empresarial, a primeira dúvida que surge diz respeito ao aspecto econômico. A ideia que prevalece é de que qualquer providência que venha a ser tomada em relação à variável ambiental traz consigo o aumento de despesas e o consequente acréscimo dos custos do processo produtivo. Algumas empresas, porém, têm demonstrado que é possível ganhar dinheiro e proteger o meio ambiente, desde que as empresas possuam certa dose de criatividade e condições internas para que possam transformar as restrições e ameaças ambientais em oportunidades de negócios (DONAIRE, 2008).

Essa abordagem considera que a inovação nas empresas não pode ser entendida como uma decisão isolada. Ao contrário, ela envolve uma concepção sistêmica em que ocorrem interações complexas entre a empresa e o ambiente em que ela está inserida. Essas relações com o entorno se dão em duas instâncias: as relações entre empresas (dentro da cadeia produtiva) e as relações entre empresas e todo o ambiente econômico-social e institucional. O cerne dessa teoria é que a ambiência em que estão inseridas vai influenciar a atitude das empresas com relação a inovação e no modo como a inovação ocorre (KIPERSTOK et al., 2002).

Desde a década de 1980, as empresas do mundo desenvolvido dão grande importância aos seus passivos ambientais. Trata-se de um enorme problema que começa a ser conhecido e divulgado e que exige soluções imediatas. A solução dos passivos deve ser preventiva - a sua não geração -, pois é mais barata, de solução mais simples e eticamente justificada (ANDREOLI, 2002). O passivo ambiental pode ser definido como o montante da avaliação contábil dos custos ambientais atuais e futuros necessários para o resgate das pendências da empresa em relação à legislação ambiental.

As organizações vêm incorporando, ainda que de forma lenta, a prática da gestão ambiental em sua estrutura. Entre as mais diversas definições do termo gestão ambiental empresarial (GAE), Barbieri (2007) a define como "as diretrizes e as atividades administrativas e operacionais, tais como planejamento, direção, controle, alocação de recursos e outras realizadas como o objetivo de obter efeitos positivos sobre o meio ambiente, quer reduzindo ou eliminando os danos ou problemas causados pelas ações humanas, quer evitando que eles surjam".

A abordagem estratégica da GAE beneficia a empresa em fatores relacionados ao ambiente interno e externo. Dessa forma, as influências desse benefício atingem a imagem da empresa, 
funcionários, linhas de produtos, processos, funcionários, fornecedores, parceiros, clientes, governo, etc. (FREDERICO, 2007). As soluções ambientais estão sendo desenvolvidas. A alternativa a ser adotada depende da estratégia da empresa, ou seja, de que metas ambientais pretendem atingir em função da relação entre condições externas e internas. No entanto, para atingir a qualidade ambiental, a empresa necessita de indicadores para medir a eficiência de suas atividades. Portanto, o uso de indicadores ambientais permite realizar melhorias nas ações implementadas, assim como direcionar novos esforços de melhoria ambiental.

Quando uma empresa desenvolve e implementa um Sistema de Gestão Ambiental manifesta, de forma implícita, o seu interesse em apresentar um desempenho ambiental em sintonia com os princípios do desenvolvimento sustentável e entende ainda, que o mercado no qual se insere busca e exige produtos e serviços menos agressivos ao meio ambiente. Assim, não está apenas cumprindo a legislação, mas também está garantindo a sua sobrevivência em um mercado globalizado cada vez mais competitivo e de cuja aceitação, depende sua saúde financeira (FOGLIATTI et al., 2011). Portanto, pode-se afirmar que o envolvimento das organizações com as questões sociais pode transformar-se numa oportunidade de negócios. A preocupação de muitas organizações com o problema da poluição tem feito que elas reavaliem o processo produtivo, buscando a obtenção de tecnologias limpas e o reaproveitamento dos resíduos. Isso tem propiciado vultosas economias, que não teriam sido obtidas se elas não tivessem enfocado este tema problema (DONAIRE, 2008).

A responsabilidade social da empresa deve voltar-se para a eliminação e/ou redução dos efeitos negativos do processo de produção e preservação dos recursos naturais, principalmente os não renováveis, através da adoção de tecnologias eficientes, concomitantemente ao atendimento dos aspectos econômicos (RIBEIRO, 1992). Destacam-se neste quesito os ativos e passivos ambientais. Os ativos ambientais são os recursos financeiros e econômicas de uma instituição que geram benefícios e destaques para as empresas que contribuem com a preservação do meio ambiente. A reputação da empresa é um importante ativo intangível que se relaciona fortemente com seu desempenho financeiro e mercadológico (BARBIERI, 2007). Já os passivos ambientais são as obrigações que a empresa possui, oriundas de qualquer ação que a mesma tenha incorrido ao meio ambiente, ou seja, a empresa que causar algum dano ao meio ambiente terá que pagar pelo ressarcimento ao dano gerado.

O problema do livre acesso aos recursos naturais sem nenhum tipo de pagamento para aquisição desses recursos, ou seja, a não existência de um mercado que valorasse os recursos produzidos e cedidos pelo meio ambiente, fez com que sua utilização fosse indiscriminada, sem nenhum tipo de preocupação com a questão da escassez ou seu uso indevido. Parece óbvio e bastante razoável imaginar que se algo útil é proporcionado a um preço zero, sua demanda será maior do que se tivesse um preço positivo, e é exatamente isso que ainda ocorre com os recursos naturais (BEZERRA, 1997).

Partindo-se do princípio de que a atividade econômica, a qualidade de vida e a coesão das sociedades humanas são profunda e irremediavelmente dependente dos bens e serviços providos pelo meio ambiente, é fundamental que a teoria econômica considere em seu arcabouço teórico as interconexões entre sistema econômico e seu meio externo, procurando compreender a dinâmica subjacente aos processos naturais de suporte à vida e os impactos que as atividades humanas têm sobre os sistemas naturais (ANDRADE, 2008). Nesse sentido, a economia ambiental, deve ser encarada como uma arma competitiva, como parte da estratégia de desenvolvimento adotada pelas empresas que pretendem lançar-se ou mesmo permanecer atuantes no mercado (COSTA, 2005). 
Com a modernidade, está havendo claramente uma redistribuição das funções econômicas no mundo. Um mesmo produto final é feito com materiais, peças e componentes produzidos em várias partes do planeta. Produzem-se os componentes onde os custos são mais adequados. E os fatores que implicam os custos de produção incluem as exigências ambientais do país em que está instalada a fábrica. Este fato tem provocado, em muitos casos, um processo de "migração" industrial. Indústrias são rapidamente montadas em locais onde fatores como disponibilidade de mão-de-obra, salários, impostos, facilidades de transporte e exigências ambientais, entre outros, permitem a otimização de custos (SILVA, 2002).

Comune (1994) diz que as modificações da qualidade do meio ambiente têm efeitos físicos, diretos, tais como a perda da capacidade de produção dos indivíduos, de produção animal, a diminuição dos rendimentos agrícolas, a redução da duração dos materiais, as perdas dos benefícios do lazer, etc. Estes efeitos constituem os danos físicos que, uma vez traduzidos em termos monetários, representam os prejuízos ou os custos que a sociedade está suportando pela modificação ambiental. As empresas precisam gerenciar seus recursos sob o enfoque ecológico e, para tanto, torna-se necessário integrar o controle ambiental com os aspectos econômicos e financeiros, a fim de melhor suportar suas estratégias e decisões, o que se converte em ganhos nos negócios e para a sociedade.

\section{CONSIDERAÇÕES FINAIS}

Neste trabalho, houve a preocupação de apresentar a forte influência da variável ambiental, entendida como a necessidade de preservação do meio ambiente no contexto da organização e gestão nas indústrias. A humanidade ao longo dos anos modificou o ambiente, modificando também as suas organizações sociais e culturais conduzindo a uma reflexão sobre os modos de produção e consumo atuais e futuros.

A complexidade dos problemas ambientais, aliada à necessidade de comunicação entre os vários setores envolvidos, requer a participação de especialistas em diversos campos: direito, economia, saúde pública, ecologia, engenharia e tantos outros, que podem contribuir para o desenvolvimento da humanidade. Dessa forma, a abordagem sistêmica e a multidisciplinaridade poderão contribuir para o aprimoramento do sistema produtivo em direção ao desenvolvimento sustentável.

Alguns aspectos, tais como, a globalização da economia, a introdução de bens de consumo e tecnologias em países cuja economia era fechada, adequação às políticas e acordos internacionais (Ex. Protocolo de Kyoto) tiveram maior inferência para a mudança dos modelos de desenvolvimento, na alteração das próprias sociedades e das concepções de sustentabilidade. Cabe ressaltar, que estes conceitos são mutáveis e sofrem influência das alterações nas práticas econômicas, conflitos, necessidades e políticas globais.

\section{REFERÊNCIAS}

ALVES, K. M. da S.; ALVES, A. E. L.; SILVA, F. M. Poluição do ar e saúde nos principais centros comerciais da cidade de Natal/RN. Holos, v.4, p. 81-95, 2009. 
ANDRADE, D. C. Economia e meio ambiente: aspectos teóricos e metodológicos nas visões neoclássicas e da economia ecológica. Leituras de Economia Política, v.14, p.1-31, 2008.

ANDREOLI, C. A. Gestão Ambiental. In: Gestão Empresarial. FAE: Gazeta do Povo, 2002. (Coleção Gestão Empresarial, v.2). p.61-70.

ANGOTTI, J. A. P.; AUTH, M. A. Ciência e Tecnologia: implicações sociais e o papel da educação. Ciência \& Educação, v.7, n.1, p.15-27, 2001.

BARBIERI, J. C. Gestão Ambiental Empresarial: conceitos, modelos e Instrumentos. 2.ed. São Paulo: Saraiva, 2007. $392 p$.

BAUDRILLARD, J. A sociedade de consumo. Lisboa: Edições 70, 1975.

BEZERRA, F. A. Reconhecendo o meio ambiente como um fator de sobrevivência empresarial. Anais do V Congreso Internacional de Costos. Acapulco, México, p. 799-808, 1997.

BRANCO, S. M. Ecossistêmica: uma abordagem integrada dos problemas do meio ambiente. 2.ed. São Paulo: Edgard Blücher, 1999

BRANDSMA, E. H.; EPPEL, J. Produção e consumo sustentáveis: um enfoque internacional. In: RIBEMBOIM, J. (Org.). Mudando os padrões de produção e consumo. Brasília: IBAMA, 1997. 147p.

BRASIL. Lei n 6.938/81: Política Nacional do Meio Ambiente. Brasília, DF, 1981.

BROWN, L. R.; ABRAMOVITZ, J.; BRIGHT, C.; FLAVIN, C.; GARDNER, G.; KANE, H.; PLATT, A.; POSTEL, S.; ROODMAN, D.; SACHS, A.; STARKE, L. State of the world 1996: a worldwatch institute report on progress toward a sustainable society. World Watch Institute: Washington, 1996.

BRUNDTLAND, G. H. Nosso Futuro Comum. Rio de Janeiro: Fundação Getúlio Vargas, 1991.

BRÜSEKE, F. J. O problema do desenvolvimento sustentável. In: CAVALCANTI, C. (Org.). Desenvolvimento e natureza: estudos para uma sociedade sustentável. São Paulo: Cortez, 1998. p.29-40.

CALLENBACH, E.; CAPRA, F.; GOLDMAN, I.; LUTZ, R.; MARBURG, S. EcoManagement: the Elmwood guide to ecological auditing and sustainable business. San Francisco: Berrett-Koehler, 1993.

CAMARGO, A. L. de B. Desenvolvimento Sustentável: dimensões e desafios. Campinas: Papirus, 2003.

CAPRA, F. A teia da vida: uma nova compreensão científica dos sistemas vivos. São Paulo: Cultrix, 1996.

CARVALHO, M. O que é natureza. 2.ed. São Paulo: Editora Brasiliense, 1999. (Coleção Primeiros Passos, 243).

CARVALHO, I. C. M. Educação, Natureza e cultura: ou sobre o destino das latas. In: ZARZKZEVSKI, S.; BARCELOS, V. (Orgs.). Educação Ambiental e compromisso social: pensamentos e ações. Erechim, EDIFAPES, 2004. p.163-174.

COMUNE, A. E. Meio ambiente, economia e economistas: uma breve discussão. In: MAY, P. H.; MOTTA, R. S. Valorando a própria natureza: análise econômica para desenvolvimento sustentável. Rio de Janeiro, Campus, 1994.

COSTA, H. S. de M. Meio ambiente e desenvolvimento: um convite à leitura. In: HISSA, C. E. V. (Org.). Saberes ambientais: desafios para o conhecimento disciplinar. Belo Horizonte: EdUFMG, 2008.

COSTA, S. S. T. Introdução à economia do meio ambiente. Análise, v.16, n.2, p.301-323, 2005.

DIÁRIO OFICIAL DA UNIÃO. Conferência das Nações Unidas sobre Meio Ambiente e Desenvolvimento: Agenda 21 Brasília: Senado Federal 1996. 
DIAS, G. F. Fundamentos de Educação Ambiental. Brasília: Universa, 1997.

DONAIRE, D. Gestão Ambiental na Empresa. 2.ed. São Paulo: Atlas, 2008. 169p.

EGRI, C. P.; PINFIELD, L. T. As Organizações e a Biosfera: Ecologia e Meio Ambiente. In: CLEGG, S.; HARDY, C.; NORD, D. (Orgs.). Handbook de estudos organizacionais. São Paulo: Atlas, v.1, 1998. p.195-219.

ERKMAN, S.; FRANCIS, C.; RAMESH, R. (Orgs.) Ecologia industrial: uma agenda para a evolução no longo prazo do sistema industrial. São Paulo: Instituto Pólis, 2005. 88p. (Cadernos de Proposições para o Século XXI, v.12)

FERRAZ, J. C. de F. Crescimento populacional, urbanização e desenvolvimento. São Paulo: EdUSP, 1991. (Boletim Técnico da Escola Politécnica da USP, 45).

FOGLIATTI, M. C.; CAMPOS, V. B. G.; FERRO, M. A. C.; SINAY, L.; CRUZ, I. Sistema de Gestão Ambiental para Empresas. 2.ed. Rio de Janeiro: Interciência, 2011. 150p.

FOLADORI, G.; TAKS, J. Um olhar antropológico sobre a questão ambiental. Mana, n.10, v.2, p.323-348, 2004.

FONSECA, M. C. L. Da modernização à participação: a política federal de preservação nos anos 70 e 80 . Revista do Patrimônio Histórico e Artístico Nacional, n.24, p.153-163, 1996.

FRANCO, M. de A. R. Planejamento ambiental para a cidade sustentável. São Paulo: Amablume, 2000.

FREDERICO, E. O que é análise do ambiente de mercado? Antenna Web, v.3, p.1-10, 2007.

GEERTZ, C. O impacto do conceito de cultura sobre o conceito de homem. In: A interpretação das culturas. Rio de Janeiro: LTC, 1989.

GIANNETI, B. F.; ALMEIDA, C. M. V. B. Ecologia industrial: conceitos, ferramentas e aplicações. São Paulo: Edgard Blücher, 2006. 109p.

GRIMBERG, E. Ecologia Industrial - um Processo em Construção. A Ecologia Industrial e a Capacidade de Suporte da Terra. In: ERKMAN, S.; FRANCIS, C.; RAMESH, R. Ecologia Industrial: uma agenda para evolução do sistema industrial. São Paulo, Instituto Pólis, 2005.

GUATARRI, F. As três ecologias. 6.ed. Campinas: Papirus, 1997. 56p.

HARDIN, G. The tragedy of the commons. Science, v.13, p.1243-1248, 1968.

HAWKEN, P. The Ecology of Commerce: a declaration of sustentability. New York: Harper Business, 1993.

HAWKEN, P.; LOVINS, A.; LOVINS, L. H. Capitalismo natural: criando a próxima revolução industrial. São Paulo: Cultrix, 2011. 358p.

HISSA, C. E. V. A mobilidade das fronteiras: inserções da geografia na crise da modernidade. Belo Horizonte: EdUFMG, 2002.

HISSA, C. E. V. Saberes ambientes: a prevalência da abertura. In: HISSA, C. E. V. (Org.). Saberes ambientais: desafios para o conhecimento disciplinar. Belo Horizonte: EdUFMG, 2008.

JACQUES, T. A. Sobre o impacto da dicotomia natureza e cultura na Antropologia. Antropologia em Primeira Mão, v.123, p.6-20, 2010.

KIPERSTOK, A.; COSTA, D. P.; ANDRADE, J. C.; AGRA FILHO, S.; FIGUEROA, E. Inovação como requisito do Desenvolvimento Sustentável. Revista Eletrônica de Administração, v.8, n.6, p.3-20, 2002. 
LAGO, A.; PÁDUA, J. A. O que é Ecologia? São Paulo: Brasiliense, 1984.

LAYRARGUES, P. P. O desafio empresarial para a sustentabilidade e as oportunidades da educação ambiental. In: LOUREIRO, C. F. B. (Org.). Cidadania e meio ambiente. Salvador: CRA, 2003, p.95-110.

LEACH, E. Natureza/Cultura. In: Anthropos-Homem. Lisboa: Enciclopédia Einaudi/INCM, v. 5, 1985. p.67-101.

LEHNI, M. Ecoficiência: criando mais valor com menos impacto. World Business Council for Sustainable Development, Genebra, Suíça, 2000. Disponível no site: http://www.wbcsd.org/. Acessado em 27 de junho de 2011.

LEIPERT, C. Social costs of economic growth. Journal of Economic Issues, v.20, n.1, p.109-131, 1986.

LIMA, J. C. F. Abordagens Industriais Ambientais: solucionar problemas de poluição ou buscar sustentabilidade ambiental? 116f. Dissertação (Mestrado em Engenharia Civil), Universidade Estadual de Campinas, Campinas, 2008.

LIMA, M. Del V.; RONCAGLIO, C. Degradação socioambiental urbana, políticas públicas e cidadania. Desenvolvimento e meio ambiente, n.3, p.53-63, 2001.

LORA, E. E. S. Prevenção e Controle da Poluição nos Setores Energético, Industrial e de Transporte. Rio de Janeiro: Interciência, 2000.

MARGULIS, L. O planeta simbiótico: uma nova perspectiva da evolução. Rio de Janeiro: Rocco, 2001.

MARQUEZ, R. P. Imagens da natureza. In: HISSA, C. E. V. (Org.). Saberes ambientais: desafios para o conhecimento disciplinar. Belo Horizonte: EdUFMG, 2008.

MONTIBELLER, F. Espaço socioambiental e troca desigual. InterThesis, p.1-20, 2004.

MORAIS, L.; BORGES, A. Novos paradigmas de produção e consumo: experiências inovadoras. São Paulo: Instituto Pólis, 2010.

NICO, A. P. F. O desenho urbano pautado pela infra-estrutura urbana. Dissertação (Mestrado em Arquitetura) Universidade de São Paulo, 2010.

ODUM, E. P. Ecologia. Rio de Janeiro: Guanabara Koogan, 1988.

PELEGRINI, S. Cultura e natureza: os desafios das práticas preservacionistas na esfera do patrimônio cultural e ambiental. Revista Brasileira de História, v. 26, n. 51, p.115-140, 2006

POMBO, F. R.; MAGRINI, A. Panorama de aplicação da norma ISO 14001 no Brasil. Gestão \& Produção, v.15, n.1, p.110, 2008.

RAZZOTO, E. Ecosustentabilidade: dicas para tornar você e sua empresa sustentável. Paraná: Absoluta, 2009. 137p.

RIBEIRO, M. S. Contabilidade e meio ambiente. 141f. Dissertação (Mestrado em Contabilidade), Universidade de São Paulo, 1992.

RIBEMBOIM, J. Mudando os padrões de produção e consumo. In: RIBEMBOIM, Jacques. (Org.). Mudando os padrões de produção e consumo. Brasília: IBAMA, 1997. 147p.

ROCHA, M.; MOTA, J. E. A. Cultura e natureza nas sociedades modernas: ensaio sobre as relações entre homem e natureza nas sociedades produtoras de mercadorias. Espaço \& Tempo, n. 30, p.150-158, 2011.

ROCHA, S. M. Mídia e meio ambiente. In: HISSA, C. E. V. (Org.). Saberes ambientais: desafios para o conhecimento disciplinar. Belo Horizonte: EdUFMG, 2008. 
ROSNAY, J. O homem simbiótico: perspectivas para o terceiro milênio. Petrópolis: Vozes, 1997.

SABLOWSKI, A. R. M. Balanço de materiais na gestão ambiental da cadeia produtiva do carvão vegetal para produção de ferro gusa em Minas Gerais. 164f. Tese (Doutorado em Ciências Florestais), Universidade de Brasília, UnB, Brasília, 2008.

SALGADO, V. G. Proposta de Indicadores de Ecoeficiência para o Transporte de Gás Natural. Dissertação (Mestrado em Ciências de Planejamento Energético), Universidade Federal do Rio Janeiro, UFRJ, Rio de Janeiro, 2004.

SANTOS, B. de S. Os processos de globalização. In: SANTOS, B. de S. (Org.). A globalização e as ciências sociais. 2.ed. São Paulo: Cortez, 2002, p.25-102.

SCHNAIBERG, A.; GOULD, K. A. Environment and Society: the enduring conflict. New York: St Martin's Press, 1994.

SCHOEMAKER, P. J. H.; SCHOEMAKER, J. A. Estimating Enviromental Lyability: Quantifying the Unknown. California Management Review, v.37, n.3, 1995.

SCHONARDIE, Elenise Felzke. Dano ambiental: a omissão dos agentes públicos. 2.ed. Passo Fundo: EdUPF, 2005. 112p.

SEIFFERT, M. E. B. ISO 14001 Sistemas de Gestão Ambiental: implantação objetiva e econômica. 3.ed. São Paulo: Atlas, 2007.

SICHER, R.; AGOSTINHO, F.; ORTEGA, E.; ROMEIRO, A. Índices versus indicadores: precisões conceituais na discussão da sustentabilidade de países. Ambiente \& Sociedade, n.2, v.10, p.137-148, 2007.

SILVA, R. C. P. Meio Ambiente e Globalização. Presença Revista de Educação, Cultura e Meio Ambiente, n.24, v.6, p.19, 2002.

SOUZA, N. J. Economia regional: conceitos e fundamentos teóricos. Perspectiva Econômica, n.32, v.11, p.67-102, 1981.

THOMAS, K. O homem e o mundo natural. São Paulo: Companhia das Letras, 1989.

ULLMANN, R. A. Antropologia Cultural. 2.ed. Porto Alegre: ESTSLB, 1983.

WAGNER, R. The Invention of Culture. Chicago: The University of Chicago Press., 1981.

WEITZMAN, M. L. On the Welfare Significance of National Product in a Dynamic Economy. The Quarterly Journal of Economics, v.90, n.1, p.156-162, 1976.

WOLÁNSKI, N. Human life and culture: dynamic components of ecosystems. Zygon, v.24, n.4, p.401-427, 1989. 